\title{
ARTIGOS
}

Submetido 08.09.2015. Aprovado 20.06.2016

Avaliado pelo processo de double blind review. Editor Científico: Rafael Alcadipani

DOI: http://dx.doi.org/10.1590/So034-759020170102

\section{REPOSICIONANDO CONCEITOS: A ORGANIZAÇÃO FORA DOS EIXOS}

\author{
Repositioning concepts: The organization out off axis \\ Reposicionando conceptos: La organización fuera del eje
}

\begin{abstract}
RESUMO
O estudo das organizações de resistência, multiplicidade de experiências sociais desperdiçadas pelo discurso organizacional dominante, é uma das ações políticas da crítica no contexto dos estudos organizacionais. Ainda que o Brasil tenha uma longa trajetória crítica na análise das organizações, as alternativas são frequentemente abordadas de modo abstrato, conceitual. Assim, por meio de um estudo de caso do tipo intrínseco, analisamos a dinâmica organizacional do Circuito Fora do Eixo (FDE), um agrupamento de coletivos de produção cultural independente, como uma organização que se encontra no limite da formação social discursiva dominante. Por meio da análise do FDE, procuramos demonstrar os limites do quadro teórico dominante no estudo sobre organizações, apresentando abordagens alternativas que parecem mais adequadas para dar conta da ordem social em que vivemos.
\end{abstract}

PALAVRAS-CHAVE | Circuito Fora do Eixo, teoria organizacional, burocracia, gerencialismo, resistência.

\section{ABSTRACT}

The study of resistance organizations, multiplicity of social experiences squandered by the dominant organizational discourse, is one of the critical political actions in the context of organizational studies. Although Brazil has a long critical path in critical analysis of organizations, the alternatives are often addressed in an abstract and conceptual mode. Thus, through an intrinsic case study, we analyzed the organizational dynamics of the Off Axis Circuit (FDE), a grouping of collectives that make independent cultural production, as an organization at the limit of the dominant discursive social formation. Through FDE analysis, we seek to demonstrate the limits of the dominant theoretical framework in the study of organizations, presenting alternative approaches that seem more appropriate to explain the social context in which we live

KEYWORDS I Off Axis Circuit, organizational theory, bureacracy, managerialism, resistance.

\section{RESUMEN}

El estudio de las organizaciones de resistencia, multiplicidad de experiencias sociales desperdiciadas por el discurso organizacional dominante, es una de las acciones políticas de la crítica en el contexto de los estudios organizacionales. Aunque Brasil tenga una larga trayectoria crítica en el análisis de las organizaciones, las alternativas frecuentemente se abordan de modo abstracto, conceptual. Así, por medio de un estudio de caso de tipo intrínseco, analizamos la dinámica organizacional del Circuito FDE - Fora do Eixo (Fuera del Eje Rio de Janeiro-São Paulo), un agrupamiento de colectivos de producción cultural independiente, como una organización que se encuentra en el límite de la formación social discursiva dominante. Por medio del análisis del FDE, buscamos demostrar los límites del cuadro teórico dominante en el estudio sobre organizaciones, presentando abordajes alternativos que parecen más adecuados para entender el orden social en que vivimos.

PALABRAS CLAVE / Circuito Fora do Eixo, teoría organizacional, burocracia, gerencialismo, resistencia. 


\section{INTRODUÇÃO}

A discussão a respeito do conceito de organização não é recente nos estudos organizacionais. Seja por meio dos questionamentos levantados pelas perspectivas pós-modernistas ou críticas (Alvesson \& Deetz, 1996) ou pela tradição do pensamento crítico brasileiro (Faria, 2009; Paula, 2001; Rodrigues \& Carrieri, 2001; Segnini \& Alcadipani, 2014), são ricos os debates acerca das limitações que a ideia dominante de organização nos impõe. De acordo com Böhm (2006), por exemplo, o conceito de organização é costumeiramente restrito à descrição do que se passa em instituições gerencialistas, empresas e locais de trabalho, posicionando a organização como uma entidade formal dentro de estruturas estabelecidas da modernidade e do capitalismo. Nestes termos, podemos dizer que a burocracia permanece como modelo estruturante das organizações na modernidade (Clegg, 1998; Paula, 2002), e, com isso, predominam características como hierarquia, existência de regras e normas, divisão do trabalho, impessoalidade das relações, controle sobre as coisas e sobre as pessoas, padronização, formalização e previsibilidade (Höpfl, 2006; Kallinikos, 2004; Motta \& Bresser-Pereira, 2004; Tragtenberg, 1980).

A centralidade do mercado na sociedade moderna acrescenta a essa perspectiva características gerencialistas que se coadunam com o modelo burocrático, tornando-o individualista e egoísta, centrado na propriedade privada, transformando objetos e seres em mercadorias, exigente de eficácia e eficiência, sem engajamento político e com pretensão à aplicação universal (Abraham, 2007; Alcadipani, 2011; Böhm, 2006; Parker, 2002; Solè, 2008).

Apesar da influência exercida pela literatura anglo-saxã sobre o campo dos estudos organizacionais no Brasil (Misoczky \& Amantino-De-Andrade, 2005; Rodrigues \& Carrieri, 2001), existe no País uma longa tradição na reflexão crítica nos estudos sobre organizações. Paula et al. (2011) e Faria (2009) ressaltam que acadêmicos nacionais já realizavam trabalhos de natureza crítica antes mesmo que se constituísse formalmente uma corrente na Europa e nos Estados Unidos, destacando o pioneirismo de autores como Guerreiro Ramos, Mauricio Tragtenberg e Prestes Motta.

Percebemos uma trajetória nacional de pesquisas que ampliam os horizontes do conceito de organização, não se restringindo à noção de empresa, mas debruçando-se sobre a análise dos mais diversos objetos a partir de múltiplas perspectivas teóricas, por exemplo, os estudos realizados sobre as organizações da economia solidária (Andion, 2005; Costa \& Carrion, 2008; França, 2003, 2007; Paula et al., 2011), as organizações autogestionárias (Faria et al., 2008; Misoczky, Silva, \& Flores, 2008; Moraes, 2010), as organizações substantivas
(Serva, 1997), a organização circense (Oliveira \& Cavedon, 2015), as escolas de samba (Tureta \& Araújo, 2013), as organizações híbridas (Wood, 2013) e a organização liminar (Meira, 2014).

De modo semelhante, temos a indicação feita por Alcadipani e Tureta (2009) a respeito da necessidade de abertura para novos horizontes teóricos que nos auxiliem na compreensão da vivência organizacional ou para o uso de abordagens processuais, conforme é sugerido por Duarte e Alcadipani (2016). Barros e outros pesquisadores enfocam o uso da perspectiva histórica da administração, mostrando uma visão alternativa no que se refere ao estabelecimento dos saberes gerenciais (Barros \& Carrieri, 2015; Barros, Cruz, Xavier, Carrieri, \& Lima, 2011). No mesmo sentido, Carrieri, Perdigão, e Aguiar (2014) argumentam que o enfoque da gestão ordinária leva em consideração os fatores históricos, sociais, culturais e identitários que diferenciam os sujeitos na prática cotidiana, pluralizando a gestão. Paula (2013) apresenta a abordagem freudo-frankfurtiana e as estratégias metodológicas da pesquisa ação e socioanálise como propostas alternativas para os estudos organizacionais, colocando a emancipação e a autonomia não só como um tema mas também como um valor a ser buscado pela própria prática da pesquisa. Complementando essas ideias, temos Dellagnelo, Böhm, e Mendonça (2014), ressaltando a possibilidade do uso da teoria política do discurso nos estudos organizacionais para auxiliar na compreensão das organizações de resistência.

Apesar da afirmação de Reedy (2014) segundo a qual a rica tradição de analisar organizações não gerenciais raramente figura nos estudos organizacionais, concordamos com Rodgers, Petersen, e Sanderson (2016) quando afirmam que o interesse da teoria organizacional acerca das organizações alternativas tem crescido. Assim, no cenário internacional, também verificamos a produção de conhecimentos sobre objetos atípicos e abordagens alternativas das organizações. As pesquisas sobre organizações anarquistas, por exemplo, demonstram possibilidades alternativas por meio do desenvolvimento de uma organização não hierárquica (Land \& King, 2014), ou, como argumentam Sutherland, Land, e Böhm (2014), nesse tipo de organização, as posições individuais de liderança são negadas, tendo seu significado redefinido pelos próprios sujeitos. Outros autores também vêm oferecendo contribuições valiosas para esse cenário, como Imas e Weston (2012) e sua análise sobre experiências e narrativas de organização e gestão dos pobres e marginalizados no Brasil e Zimbábue; Schneiberg, King, e Smith (2008), sobre a contribuição dos movimentos sociais para a diversidade institucional; Spicer e Böhm (2007), sobre organizações e movimentos de resistência; Ibarra-Colado (2006), com a reflexão sobre a necessidade de superarmos o colonialismo nos estudos organizacionais; e Cheney, Cruz, Peredo, e Nazareno 
(2014), cujo destaque são os principais desafios enfrentados pelas cooperativas no contexto atual.

Estudos como esses evidenciam que as forças que buscam um posicionamento absoluto da realidade sempre estarão sujeitas à resistência. Esta é uma das ações políticas da crítica no contexto dos estudos organizacionais. As organizações de resistência, portanto, são apontadas como espaços de construção de possibilidades alternativas de organização, no sentido de trazer à tona a existência de uma multiplicidade de experiências sociais desperdiçadas pelo discurso organizacional dominante (Santos, 2002). Nesse sentido, Carrieri (2004), Misoczky, Flores, e Böhm, (2008), Morais e Paula (2010), Zilio, Barcellos, Dellagnelo, e Assman (2012) e Barcellos, Dellagnelo, e Salles (2014), entre outros autores, enfatizam experiências de organizar que desafiam o modelo dominante.

Visando colaborar com esse debate, apoiamo-nos na força de um caso empírico, esforço que não é comum na trajetória crítica nacional, para trazer à luz uma experiência de organizar que se contrapõe ao pensamento dominante. Assim, neste trabalho, analisamos a dinâmica do organizar do Circuito Fora do Eixo (FDE), um coletivo cultural, como uma organização que se encontra no limite da formação social discursiva dominante, resistindo à realidade das organizações continuamente produzida pelos acontecimentos do projeto moderno (Barcellos \& Dellagnelo, 2013). Sua existência é possível, pois nenhuma hegemonia consegue dar conta de toda a realidade social, sendo sempre desafiada por forças de subversão e resistência (Laclau \& Mouffe, 2001).

Assim, concordamos com Reedy (2014), segundo o qual as alternativas são frequentemente abordadas de modo abstrato, conceitual, e, a fim de que possamos demonstrar um organizar considerado impossível pela literatura dominante, faz-se necessário analisar mais detalhadamente as práticas cotidianas de grupos protagonistas.

Por meio da análise do FDE, procuramos demonstrar os limites do quadro teórico dominante no estudo sobre organizações. Na medida em que nos aproximamos do FDE, percebemos que seu fluxo contínuo e sua dinâmica particular dificilmente se enquadram sob as lentes das teorias dominantes nos EOs. Ao contrário, há uma multiplicidade de abordagens, cada qual com suas contribuições, capazes de auxiliar na compreensão de aspectos diversos de uma organização em constante movimento, uma organização de organizações, com suas múltiplas dimensões. Assim, apresentar um caso empírico não adequado à teoria dominante expõe as fragilidades da abordagem teórica que se apresenta como suficiente para dar conta da ordem social em que vivemos.

Portanto, nosso objetivo neste trabalho é evidenciar a limitação do uso de um enfoque teórico dominante, apostando na multiplicidade de visões sobre diferentes aspectos organizacionais que serão destacados. Para isso, apresentamos, na sequência, os procedimentos metodológicos utilizados em nossa pesquisa com o FDE e, em seguida, discutimos seus processos organizacionais, contrapondo-os aos conceitos burocráticos e gerenciais. Ao mesmo tempo, recorremos a pesquisas desenvolvidas anteriormente as quais, no nosso entendimento, ajudam a compreender a dinâmica organizacional do FDE. Após a apresentação do caso, colocamos as considerações finais, destacando nossas reflexões sobre o aprendizado alcançado.

\section{PROCEDIMENTOS METODOLÓGICOS}

A investigação social é uma práxis distintiva que, ao ser executada, transforma a própria teoria e os próprios objetivos que a orientam, de modo que a ação e o pensamento, a prática e a teoria estão ligadas em um processo contínuo de reflexão e de transformação (Schwandt, 2006). Nesse processo, a escolha das práticas de pesquisa depende das perguntas que são feitas, as quais, por sua vez, dependem do seu contexto e do que o pesquisador pode fazer naquele cenário (Denzin \& Lincoln, 2006).

Nesta pesquisa, optamos por um estudo de caso intrínseco, estratégia de pesquisa sugerida por Stake (2000) quando há um caso que desperta interesse em si. No estudo de caso intrínseco, investiga-se um fenômeno no contexto da vida real, buscando todas as particularidades do fenômeno em sua especificidade histórica (Stake, 2000). A intenção, ao utilizar essa estratégia, foi compreender a situação em profundidade, enfatizando seu significado para os indivíduos envolvidos no processo. Entendemos o FDE como uma oportunidade ímpar de aprendizado sobre processos organizacionais alternativos e suas aproximações e distanciamentos do modelo dominante, ou seja, nos interessamos pelo caso em si, com todas as suas particularidades, caracterizando-se o trabalho como um estudo de caso intrínseco (Stake, 2000).

Coletamos os dados sobre a organização no período de outubro de 2010 a setembro de 2012. Inicialmente, acompanhamos o Circuito por meio de sites, blogs, palestras e vídeos disponíveis na internet, já que o FDE tem uma estratégia forte de exposição, havendo abundância de material disponível nesse tipo de mídia. No início de 2011, estabelecemos o primeiro contato pessoal com o FDE, recebendo autorização e amplo incentivo para o desenvolvimento da pesquisa, em forma de disponibilidade irrestrita dos membros para colaborar com o processo de levantamento dos dados. Esse processo ocorreu por meio de observação direta, entrevistas e dados secundários. 
Observamos o cotidiano de organização pelo acompanhamento de fóruns e listas virtuais de discussão de março de 2011 a setembro de 2012. Entrevistamos dois fundadores do Circuito em atividades relacionadas ao FDE na cidade de Florianópolis. Assistimos a uma reunião do Ponto de Articulação Nacional e, em setembro de 2012, participamos de uma imersão na Casa Fora do Eixo São Paulo (Cafesp). Durante três dias, vivenciamos o cotidiano da Casa, recebemos informações sobre o surgimento e a evolução do circuito e participamos de atividades como a organização da festa de aniversário da Revista Fórum, que ocorreu no terceiro dia. Nesse período, entrevistamos oito moradores, entre eles dois fundadores, três gestores e três membros mais recentes. Entrevistamos também três membros que não residiam na Casa e quatro pessoas que não fazem parte dos coletivos, mas são parceiros do circuito. As entrevistas tiveram como objetivo compreender a história da organização a partir dos relatos de seus participantes e os significados atribuídos por eles às questões de interesse da pesquisa (Godoy, 2006).

Os dados secundários tiveram origem em uma série de documentos aos quais o FDE nos permitiu acesso, como: e-mails, planilhas, banco de atas, regimento interno, carta de princípios e modo de organização. Além disso, analisamos depoimentos sobre o FDE disponíveis na internet.

A análise dos dados, em consonância com a perspectiva qualitativa, foi interpretativa e ocorreu ao longo e depois da coleta de dados. De acordo com Godoy (2006), esse tipo de análise é coerente com o estudo de caso qualitativo, devendo ser desenvolvido de modo concomitante e/ou cíclico com a coleta de dados. As reflexões que apresentamos a seguir são o resultado desse processo cíclico, de maneira que a teoria e a prática se coadunam, procurando oferecer uma visão mais abrangente do fenômeno em estudo.

\section{APROXIMANDO-SE DO MODO FORA DO EIXO DE ORGANIZAR}

O FDE é um coletivo de produção cultural independente composto por cerca de 200 coletivos presentes em todos os estados brasileiros. No contexto das transformações ocorridas na indústria fonográfica na década de 1990 (Marchi, 2011; Nakano, 2010) e na política do Estado brasileiro na área da cultura com a chegada da esquerda ao poder em 2002 (Rubim, 2010), o FDE surge em 2005 como uma alternativa para que artistas fora do eixo geográfico Rio de Janeiro-São Paulo viabilizassem a produção, circulação e distribuição de produtos e experiências culturais marginalizadas pelas estruturas de produção cultural dominantes no País, o chamado mainstream.
Os coletivos articulados pelo FDE, chamados no âmbito local de Pontos Fora do Eixo, existem em mais de 180 cidades brasileiras e atuam de maneira autônoma localmente, mobilizando diretamente cerca de duas mil pessoas. Em algumas cidades, os coletivos existem na forma de Casas Fora do Eixo, locais nos quais os membros dos coletivos residem e trabalham. Essas Casas, como pudemos observar na imersão realizada na Cafesp, são espaços de vida e trabalho para os membros, mas são também espaços simbólicos que evidenciam socialmente a existência da organização.

Da conexão oportunizada pela articulação local dos coletivos, surgem instâncias como: Colegiados Regionais, Frentes Temáticas, Simulacros e Casas Regionais. Essas instâncias representativas e executivas são formadas por membros dos coletivos locais que se autoindicam. E, no âmbito nacional, as decisões são tomadas pelo Ponto de Articulação Nacional, instância deliberativa virtual, com cerca de 140 representantes autoindicados. A Figura 1 ajuda a compreender a estrutura política do FDE:

\section{Figura 1. Modo de organização político}

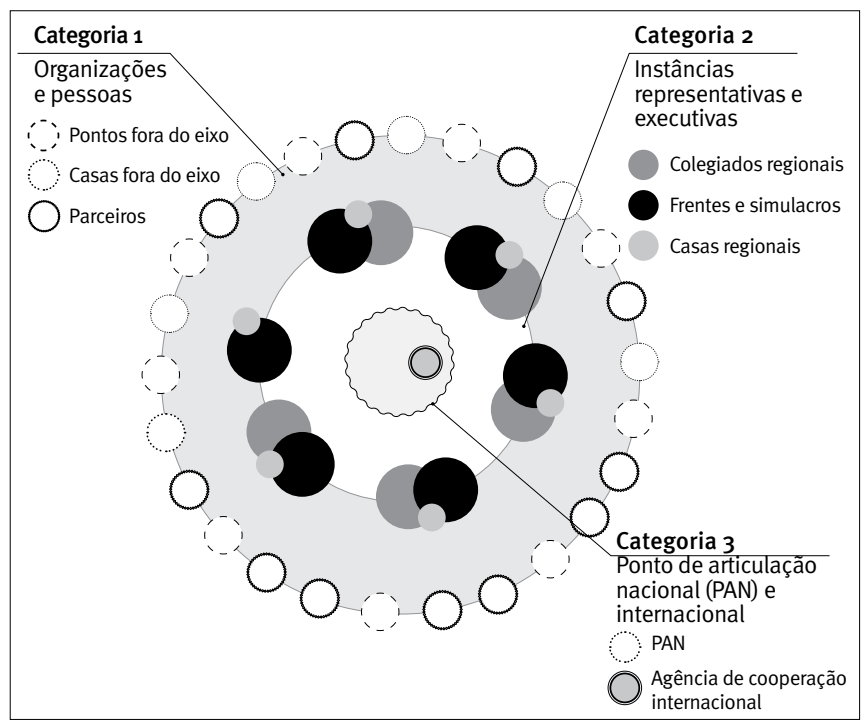

Fonte: Recuperado de Portal Transparência Fora do Eixo (2013)

A figura procura demonstrar o esforço de organização do Circuito, tanto pela sistematização de uma estrutura de trabalho como pela opção por uma estrutura que contribua para articulação dos interesses de diferentes grupos. Apesar da estrutura formal, o FDE não é formalizado por meio de inscrição no Cadastro Nacional de Pessoas Jurídicas (CNPJ) ou outro tipo de registro legal. Quando necessário, o FDE utiliza o CNPJ de um dos 18 coletivos, que o disponibiliza para ocasiões como a participação em editais, por exemplo. Entendemos o uso compartilhado desses registros 
como forma de recusa à propriedade, se considerarmos que o CNPJ é um aspecto importante de identificação das organizações formais no nosso contexto institucional, viabilizando vínculos com Estado ou iniciativa privada.

0 modo de organizar político representado na Figura 1 foi idealizado no primeiro Congresso Fora do Eixo, realizado no Acre, em 2009, quando membros do FDE perceberam que, para viabilizar a circulação e distribuição de produtos culturais fora da cadeia produtiva da música no Brasil, seria necessária uma estrutura capaz de articular os esforços dos diferentes coletivos. Conforme pudemos observar, até aquele momento, o organizar do Circuito era produzido essencialmente nas discussões realizadas por meio de listas de e-mails, conversas on-line e compartilhamentos espontâneos de "modos de fazer" entre coletivos. Naquela oportunidade, foram elaboradas as primeiras versões do Regimento Interno, da Carta de Princípios e do Modo de Organização, revelando que a organização passa a se preocupar com certo nível de formalização, com o registro em documentos de alguns princípios e regras.

Esses documentos sofrem periodicamente revisões coletivas, para adaptá-los às novas situações enfrentadas pelo Circuito. Nessas revisões, observamos que há constante atenção às nomenclaturas e formas dadas às representações gráficas, de maneira que, em oposição a termos como organograma e estrutura, são adotados termos como "modo de organizar" e “modo de organizar político". A representação circular da estrutura sugere o distanciamento da noção burocrática de hierarquia, quer na sua forma tradicional (Motta \& Bresser-Pereira, 2004; Tragtenberg, 1980), quer na sua forma flexível (Fournier \& Grey, 1999; Höpfl, 2006).

Ainda quanto à formalização, ela foi percebida em práticas como editais para a seleção de membros para imersão em Casas Fora do Eixo. No entanto, a formalização parece ser adotada para atender à necessidade de democratização das oportunidades criadas pelo Circuito, por meio de mecanismos que tornem os processos transparentes e acessíveis a todos os interessados.

A necessidade de organizar vivenciada pelo FDE vai ao encontro do proposto por Malatesta (1927), para quem a organização é a prática da cooperação e da solidariedade, uma condição natural e necessária da vida social, inextricável da sociedade humana e de todo grupo que tenha algum objetivo a alcançar. O que importa é como organizar, rejeitando o hierarquismo em sua essência de constituir um grupo ao qual cabe (co)ordenar os demais. Moraes (2010) reforça essa perspectiva ao afirmar que as regras de tomada de decisão precisam ser conhecidas por todos, o que apenas pode acontecer se estão formalizadas, portanto a normalização não implica a imposição de um modelo de heterogestão.
Desse modo, apesar de um movimento de verticalização, o qual se expressa por meio da constituição de instâncias deliberativas, a representação se coloca como uma forma encontrada pelo FDE para viabilizar a participação nas tomadas de decisão. Para isso, mescla práticas de atuação e decisão direta com práticas de representação, predominando a horizontalidade.

Essa dinâmica alinha-se ao proposto por Malatesta (1927), cujo argumento esclarece que, se uma organização for baseada na plena autonomia dos indivíduos e grupos, ainda que sofra com as imperfeições da representatividade, estará isenta de autoritarismo, pois não há imposição das decisões. A atuação direta dá-se pela participação ativa dos membros nos seus respectivos coletivos, com a plena autonomia que estes têm na sua gestão.

Além disso, a noção de comando e subordinação é subvertida pela ampla diversidade de responsabilidades assumidas por todos. Assim, o indivíduo que é responsável por um processo coloca-se a serviço de outro em momentos diversos, tecendo uma teia de relações que não permite estabelecer escalonamento ou hierarquização entre as pessoas, ainda que haja figuras de liderança com maior evidência em determinados momentos. Essa diluição de uma personalidade representativa do Circuito parece coerente com a forma como se exerce o poder na vivência cotidiana dos coletivos. Uma das pessoas entrevistadas nos afirmou que a lógica do FDE não é hierárquica:

[...] a gente consegue, enquanto fora do eixo, lidar de uma maneira muito rizomática - digamos assim - com o que já se propõe nesse campo, não hierárquica. É claro que há níveis de coordenação dentro do movimento, mas eles são oscilantes e circunstanciais. Se hoje, por exemplo, alguém é coordenação no fora do eixo, quer dizer que ontem foi base e amanhã vai ser base de novo - se coordena um núcleo, é provavelmente base em outro. (Entrevistado 1)

Embora os membros do Circuito afirmem que as atividades de coordenação são temporárias e que não há o exercício de uma liderança formal, consideramos que a liderança é um aspecto polêmico na dinâmica do FDE. Não há como ignorar a destacada atuação de um de seus membros, Pablo Capilé. Capilé tem sido um dos principais interlocutores do FDE com a mídia e o principal articulador em reuniões do Colegiado. Em nossa imersão na Cafesp, esse protagonismo ficou evidente em momentos como a chegada de autoridades políticas a um evento que ocorria na Casa, quando Capilé era chamado para receber os convidados. 
Sobre esse aspecto, parece interessante considerar a posição de Freire (2005), para quem a liderança é necessária ao processo de organização da luta. Nesse sentido, o papel de liderança de Capilé no FDE poderia ser visto como um exercício de "fazer junto com" em vez de "fazer para". Na entrevista que fizemos com Capilé, ele afirmou que havia uma preocupação manifesta de todo o FDE em diluir sua imagem de líder, articulando outros agentes.

Esse movimento relativamente vertical tende a ser compensado, em parte, pela autonomia que os coletivos dispõem para tomar suas decisões, definir sua atuação local, e pela autonomia dos agentes em seus processos de trabalho, numa perspectiva de autogestão. Moraes (2010) sugere que a autogestão é a produção de meios em uma organização que declina de qualquer estrutura hierárquica, coerente com os princípios da liberdade e igualdade, na qual todos têm direitos iguais à participação. No FDE, não há o exercício da autoridade de uns sobre outros, pois o integrante que assume a coordenação em um determinado processo assume tarefas operacionais em outros. Nesse sentido, consideramos na seção seguinte como o organizar coletivo acontece no cotidiano.

\section{O COTIDIANO DE PRODUÇÃO COLETIVA DO FDE}

No FDE, procura-se decidir predominantemente por consenso. De acordo com Innes (2004), para ser considerado consenso, é preciso a inclusão de todos os interessados na decisão, participantes que decidam suas próprias regras, definam suas agendas e tenham pleno acesso às informações. No FDE, o consenso é considerado muito importante para qualificar as decisões tomadas, como explica um membro:

[...] a gente evita votar porque a democracia é a ditadura da maioria, e o cara que não é convencido de que a pauta dele não é a melhor naquele momento, ele pode não se comprometer tanto com a ação quanto se ele estiver convencido. Então, a gente acha que vale mais a pena esgotar um debate por horas do que "tratorar" uma opinião muito sólida de uma pessoa que seja. (Entrevistado 9)

Em contraste com a eficiência, foco das organizações burocráticas, no FDE prevalecem as decisões tomadas a partir de diálogos, não impondo limites de tempo e conteúdo e viabilizando o acesso às informações a todos os participantes.
Essa característica vai ao encontro do relatado por Misoczky et al. (2008) e Misoczky et al. (2008) em casos como o da resistência às papeleiras e o das mães da Praça de Maio, ambos na Argentina. Uma questão controversa é o fato de que a participação e a fala são aceitas na medida da dedicação e contribuição do indivíduo para o coletivo. Internamente, isso é chamado de “lastro para fala", conforme ilustra uma pessoa entrevistada:

Num ambiente como esse, com muitas pessoas, onde todo mundo se acha genial, todo mundo acha que sabe de tudo, que entende de tudo, se a gente não criasse um campo de normatização, seria uma loucura, um debate eterno. Para poder estruturar isso é que temos como princípio o construir lastro pra fala. Ou seja, a sua ocupação de espaço, o tanto que você vai falar, o tanto que a sua voz vai repercutir, está muito ligado ao tanto que você está trabalhando. Pensando localmente, você vai montar um coletivo, aí vai ter aquele cara que só vai na reunião do sábado, e chega na reunião do sábado e sai falando blá blá blá. Só que na segunda-feira ela não está lá para fazer aquela ideia genial acontecer. Aí você tem que falar com o cara: seguinte, construir lastro para fala - se você não estiver aqui todo dia, o tanto que você vai falar vai ser proporcional ao tanto que você trabalha, e isso em todas as esferas. (Entrevistado 3)

Observamos que o "lastro para fala" restringe a fala àqueles que são percebidos como efetivamente comprometidos e dedicados ao FDE, de modo que, com a convivência e a imersão profunda na dinâmica do grupo, tende a haver um alinhamento intenso de visões. Ainda, tamanha imersão estabelece uma vida coletiva na qual o indivíduo está sob constante avaliação do grupo, o que pode favorecer posturas de aceitação diante dele, com a finalidade de evitar confrontos.

No FDE, há um esforço para o compartilhamento massivo de informações. Todos os documentos da organização estão disponíveis em uma base de dados de livre acesso a qualquer integrante do Circuito.

Além disso, nas listas de e-mails do Circuito, veiculam-se diariamente relatos de experiências locais, editais de vivência e de financiamento externos, informações sobre cursos e eventos, entre outros assuntos, disseminando a informação por todo o Circuito.

As redes sociais e tecnologias são amplamente utilizadas e alimentadas pelos coletivos, proporcionando uma intensa 
conexão entre integrantes do FDE. Destacamos também que a comunicação é colaborativa, já que qualquer integrante pode interferir na discussão, lançar uma pauta para o banco de pautas que organiza as comunicações de abrangência nacional do Circuito ou para serem discutidos em reuniões gerais. A colaboratividade e o compartilhamento evitam o acesso privilegiado às informações, em oposição à tradição gerencialista na qual o acesso à informação é controlado e restrito a poucos (Parker, Fournier, \& Reedy, 2007).

\section{AS RELAÇÕES DO FDE E SEUS INTEGRANTES}

Na parede da cozinha da Cafesp, durante nossa estada, um quadro informava: "Hoje somos 24 moradores". As chamadas Casas Fora do Eixo são sedes-moradia nas quais os integrantes vivem e trabalham. Adotadas depois de certo tempo por mais de 20 coletivos, nas CAFEs, o compartilhamento dos modos de vida busca criar relações altamente personalizadas, muito diferente da impessoalidade das organizações burocráticas (Kallinikos, 2004; Motta \& Bresser-Pereira, 2004; Tragtenberg, 1980).

Nesses espaços, as pessoas compartilham os meios físicos de produção, como computadores, internet e energia elétrica, e também os meios para a produção da vida cotidiana de seus moradores: dormitórios, refeições, banheiros, roupas. É uma experiência radical de compartilhamento, vista também como uma tecnologia de gestão:

Nós entendemos a CAFE como uma tecnologia de gestão. Se cada um fosse alugar um lugar para morar, seriam 16 contas de aluguel, de luz, de água, de telefone, de internet. Além disso, com todo mundo morando e trabalhando no mesmo lugar, a gente tem muito menos problemas de comunicação. (Entevistado 6)

As CAFEs ampliam a visibilidade do Circuito e têm importância simbólica para os integrantes do FDE, pois concretizam socialmente uma experiência de organização. São comunidades nas quais a vida individual é subordinada à coletiva, de maneira avessa ao individualismo que caracteriza um dos pressupostos fundamentais do mundo moderno (Dumont, 2000).

Uma das tecnologias que dão sustentação a esse modo de vida é a prática do caixa coletivo, existente nas Casas Fora do Eixo e também nos coletivos. O caixa coletivo consiste em um recipiente de madeira e um livro-caixa. É também uma conta bancária a que todos os integrantes da Casa têm acesso.
Os integrantes da CAFEs, por exemplo, convivem com essa dinâmica. A exigência, pactuada entre todos, é que todo gasto seja anotado no livro-caixa para que se saiba de quanto se dispõe. O caixa coletivo é provisionado por toda arrecadação, individual ou coletiva, de trabalhos dentro ou fora do FDE. Com essa arrecadação, são pagas as despesas dos moradores da casa, como: alimentação, luz, internet, cigarros, gasolina, vestuário.

$\mathrm{Na}$ visão dos integrantes, o caixa coletivo potencializa o coletivo porque são várias pessoas trabalhando em prol do desenvolvimento do coletivo. O caixa coletivo é, ainda, uma experiência cuja sobrevivência individual está atrelada ao que o coletivo consegue realizar. Conforme um entrevistado:

é um trabalho mesmo de desapego aqui. Existe toda uma cultura onde a gente cresceu pra ter um ótimo emprego, [...] mas entender que você consegue dessa forma (caixa coletivo) atender todas as suas necessidades sem precisar desse tipo de acúmulo. Aqui na casa a gente não acumula grana, mas todo mundo tem tudo o que precisa: computador pra trabalhar, comida, cigarro, Coca-Cola todo dia no almoço, todo dia tem [...] E as coisas que não estão dentro desse campo, que é o chocolate que eu gosto, eu pego o dinheiro do caixa e compro e todo mundo tem isso. [...] a gente consegue conviver muito bem no coletivo com todo mundo e com um respeito muito grande pela individualidade de cada um, das necessidades individuais de cada um. (Entrevistado 5)

Na prática, como os integrantes da CAFE têm autonomia para a realização dos gastos, o caixa coletivo implica pensar coletivamente, demandando solidariedade e responsabilidade na utilização dos recursos. Aliás, a noção de propriedade pareceunos bastante difusa nos coletivos, tendo em vista que o espaço e os recursos de trabalho, a residência e os recursos materiais são de posse de todos. Essa perspectiva se opõe à noção de propriedade, elementar nas formas organizacionais dominantes (Abraham, 2007; Proudhon, 1988; Solé, 2008; Tragtenberg, 1980).

A forma alternativa de relação entre os indivíduos e o FDE também foi observada na maneira como organizam e dividem o trabalho. Percebemos que as atividades são exercidas de acordo com a afinidade das pessoas para sua execução, independentemente do seu conhecimento técnico ou experiência prévia. Algumas frentes de atuação do FDE surgiram justamente desses desejos de pessoas que assumiram o desafio de desenvolver novos focos de atuação para o Circuito. Um entrevistado nos contou: 
Eu entrei sem saber nada de comunicação, mas eu queria entrar na comunicação e estou até hoje trabalhando com comunicação, mas já trabalho com produção, enfim, conheci outras áreas da cadeia cultural [...] tem muita gente que entra sem conhecimento em nenhuma área e como eu, aprendi tudo de comunicação e hoje estou trabalhando com isso. Então tem toda a cadeia de produtores e agentes FDE trabalhando por afinidade de produção mesmo. (Entrevistado 6)

Essa forma de pensar as tarefas diverge da maneira dominante de divisão do trabalho da racionalidade burocrática, na qual as pessoas são alocadas, de acordo com suas capacidades técnicas, em cargos dispostos hierarquicamente (Kallinikos, 2004). Uma outra divergência em relação à divisão do trabalho das burocracias, discutida por Prestes-Motta e BresserPereira (2004) entre outros autores, é a inexistência de funções fixas, já que no FDE as atividades dependem das demandas do coletivo. Dessa forma, embora não seja formal, há uma prática constante de troca de atividades entre os integrantes, incluindo as posições de liderança, de modo que buscam o exercício do poder alternadamente, de acordo com a natureza da atividade que está sendo desenvolvida, contrastando com a premissa burocrática de comando e obediência (Höpfl, 2006).

O FDE pretende que o desenvolvimento do indivíduo seja traçado por ele mesmo, havendo abertura para o desenvolvimento dos mais diversificados projetos. Para dar suporte a esse processo de desenvolvimento, são proporcionadas oportunidades de aprendizado, organizadas e articuladas pela Universidade Fora do Eixo. A Universidade busca estimular o debate e a geração de novas metodologias de formação, a partir da premissa de livre acesso ao conhecimento. No entanto, essa estrutura é entendida pelo FDE como um simulacro, já que desenvolve práticas organizacionais próprias, em oposição às práticas das organizações hegemônicas às quais elas se contrapõem. As formações são baseadas em experiências empíricas, ou seja, o FDE não nutre suas práticas em modelos teóricos, embora tenha algumas inspirações nesse sentido, como explica uma das pessoas entrevistadas, ao referir-se ao conceito de Zonas Autônomas Temporárias (Bey, 2001):

Nós somos o império do empírico. [...] não foi a partir da leitura do TAZ que a gente promoveu um processo de criação de zonas autônomas temporárias, por exemplo. A gente conseguiu um nome pra dar pra uma coisa que a gente já fazia. (Entrevistado 7)
A máxima do Circuito é "aprender fazendo", conforme sugere a pedagogia freireana, e isso decorre da intensa interação entre seus integrantes. Essas oportunidades de aprendizado são entendidas como o maior ganho que os membros do Circuito podem ter. Em um contexto onde a escassez de recursos financeiros é uma realidade, o FDE está constantemente debatendo que o principal retorno que as pessoas obtêm em seus trabalhos é a realização de projetos grandiosos e a construção de iniciativas de longo prazo em prol da área cultural e da emancipação da juventude. Essa realidade contrapõe-se ao estudo de Magro e Coutinho (2008), por exemplo, para quem os trabalhadores em organizações caracterizadas como autogestionárias percebem como sentido primordial do trabalho a subsistência, a qual ocorre na medida em que o trabalho se transforma em dinheiro e permite acesso ao consumo de bens e serviços.

A ausência de remuneração individual e o caixa coletivo sinalizam aos membros do FDE restrições em termos de acúmulo de bens materiais, algo que difere de maneira assaz da forma burocrática de organizar, na qual os indivíduos recebem remuneração financeira individual como recompensa dos seus trabalhos (Tragtenberg, 1980). Essa dinâmica também contrasta com a lógica gerencialista, segundo a qual sujeitos são percebidos como recursos para mais-valia e avaliados pela capacidade de retorno econômico (Böhm, 2006).

O sentido do trabalho para os membros do FDE também merece destaque. Integrantes do Circuito parecem nutrir alto comprometimento com a organização, manifestado por suas visões de futuro e na dedicação que empregam em seu trabalho no dia a dia. A dedicação em tempo integral ao FDE - de segunda a segunda, com carga diária de cerca de 12 horas - é entendida como parte da vida das pessoas, já que a maioria parece perceber vida e trabalho como aspectos convergentes em suas experiências. Podemos perceber isso na fala desta pessoa:

Dizem que a gente no FDE trabalha demais. A gente não trabalha, a gente vive. $A$ gente não concebe o trabalho como um espaço separado na vida. A vida pra gente é um fluxo contínuo de 12, 16 horas, onde a gente está vivendo essa construção que é o FDE. (Entrevistado 11).

Esse cenário opõe-se à concepção burocrática de relação organização e indivíduo, a qual se fundamenta no cargo ocupado pelos indivíduos, sendo vida pessoal e trabalho considerados aspectos disjuntos (Kallinikos, 2004).

Quanto ao futuro, os rumos do Circuito parecem ser definidos à medida que as situações acontecem, havendo pouco 
ou quase nenhum planejamento formal. Percebemos, também, que não há ênfase em resultados, o foco é centrado nos meios, em como as coisas são feitas, numa perspectiva substantiva, contrariando a necessidade de previsibilidade e a dinâmica de controle prevalente na burocracia (Clegg, 1998) e alimentada pelo gerencialismo (Chanlat, 1999; Klikauer, 2015; Parker, 2002). Como afirma um entrevistado:

A gente não se preocupa com aonde quer chegar, e sim em como estamos fazendo as coisas, num foco muito mais no processo do que nos fins. [...] não saber para onde está indo habilita muitos "ondes" possíveis, que vão sendo construídos pelos “como". (Entrevistado 8)

As propostas de atuação futura do FDE, feitas para prazos curtos, consideram a prática dos sujeitos em seus cotidianos, de modo que as ações traçadas são elaboradas em resposta à situação que os coletivos vão encontrando em suas realidades. Tal condução segue no mesmo sentido exposto por Moraes (2010) a respeito de uma construção paciente e cotidiana do organizar, um processo constantemente renovado e transformado com foco no presente, uma vez que ele é a realidade a ser transformada.

A não preocupação com a previsibilidade é vista pelos membros do FDE como uma característica positiva, que permite uma atuação orgânica do Circuito e que suas ações sejam realizadas na mdida do necessário.

Outra prática relevante na relação entre membros e FDE é a adoção do CARD, uma moeda complementar que estrutura um banco de tempo (Barcellos \& Diniz, 2016). Um banco de tempo é uma forma de ajudar alguém e de receber ajuda em troca, utilizando um sistema igualitário baseado no tempo, no qual uma hora de trabalho corresponde a uma unidade de moeda complementar, qualquer que seja a tarefa envolvida nesse sistema de troca (Boyle, 2003; Collom, 2011; Fraňková, Fousek, Kala, \& Labohý, 2014).

Nesse sistema, prevalece a prática de equivalência da remuneração por hora trabalhada, de modo que qualquer trabalho desenvolvido no FDE por seus integrantes é remunerado com base nas horas trabalhadas, independentemente da complexidade da tarefa. Um entrevistado explica como funciona:

[...] Com o Cubo Card, já que não tinha a grana, a gente começou a pagar em serviço mesmo, e aí que a gente percebeu que foi um sistema que fechou com perfeição, porque você vai lá, faz o show e recebe 400 Cubo Cards, e você vai gastando ele em ensaio, em assessoria de imprensa, na gravação, e é um novo jeito de a banda se sustentar e sustentar a sua música. (Entrevistado 6)

O sentido do CARD reside na valorização equivalente do trabalho, o que se opõe à tradição burocrática de hierarquias salariais e parece alinhado às iniciativas de autogestão descritas por Faria et al. (2008).

De acordo com Echeagaray (2011), a moeda complementar cria um sistema de valor autônomo com relação ao sistema hegemônico, criando mercados solidários independentes dele. Essa contra-hegemonia tem sido uma importante luta política do FDE e manifesta-se em diversas práticas como o CARD, mas também naquelas descritas nas seções em que relatamos o modo de organizar, de produzir e de se relacionar do FDE.

\section{REFLEXÕES FINAIS}

Spicer, Alvesson, e Kärreman (2009), inspirados em Foucault, sugerem que uma abordagem interessante para as organizações alternativas seria a da heterotopia. Heterotopias significam outros lugares, espaços de ação que encorajam a exploração e a imaginação de maneiras alternativas de ser e fazer. Entendemos que essa reflexão vai ao encontro do que evidenciamos com a análise da produção cotidiana do organizar Fora do Eixo. Um lugar que nos permite nutrir um senso de possibilidades, o que não significa que não existam problemas, disputas e conflitos. Assim, as organizações alternativas nos oferecem a possibilidade de rever nossa compreensão sobre a natureza dos conflitos em uma organização.

Conforme apontamos neste trabalho, existem diferentes possibilidades teóricas para a análise do FDE. Poderíamos ter analisado o FDE a partir da literatura sobre autogestão, economia solidária, anarquismo, entre outras, mas optamos pela perspectiva da resistência, apoiando-nos no pensamento de Laclau e Mouffe (2001). Percebemos que aspectos plurais da organização demandavam olhares igualmente plurais. Assim, o olhar sobre a moeda complementar a partir da ótica da economia solidária é esclarecedor, ao mesmo tempo que a compreensão do FDE como organização de resistência evidencia as nuances políticas e de luta, fundamentais para o entendimento da atuação histórica e contingente do FDE no contexto cultural brasileiro. Ela é uma organização que se engaja numa luta contra-hegemônica no campo da cultura, desafiando a compreensão dominante sobre o termo, e também na busca por alternativas de organização do trabalho, ressignificando uma série de processos, como tomada de decisão, distribuição das tarefas, comunicações e mecanismos de recompensa. 
Percebemos, na experiência do FDE, uma dinâmica de decisão com base em colegiados que se estruuram na transparência das informações, no consenso e na horizontalidade. Conforme as narrativas e observações, vimos também que existem regras formalizadas e divisão de tarefas, sem haver, no entanto, adoção da lógica burocrática. Essas características estão contextualizadas em um espaço organizacional cujo surgimento remete a uma disputa política em torno da possibilidade de se fazer cultura em uma sociedade caracterizada pela predominância do mercado como instância definidora do que é ou não cultura. Nesse sentido, o objetivo pelo qual o FDE se orienta, um outro entendimento de cultura, se reflete na sua prática cotidiana, articulando uma atuação coerente com seus princípios. Portanto, as práticas organizacionais são adotadas para contribuir com o alcance de objetivos coletivamente pactuados. Para isso, parece ser necessário que estejam subordinadas ao consenso, à igualdade de oportunidades, ao diálogo e à temporalidade que privilegia os relacionamentos. Mas, ainda assim, são sujeitas à contradição, ao conflito e ao questionamento como aspectos inerentes de qualquer espaço social.

Dessa forma, como argumentam Parker et al. (2007), a contradição não é algo a ser temido ou eliminado, pois, se não houvesse tensões ou conflitos em um conjunto particular de ideias, seria difícil imaginar que essas ideias estejam vivas, em movimento.

Nós entendemos que o FDE está inserido em uma sociedade na qual a articulação hegemônica está constantemente buscando formas de incorporar à sua formação discursiva elementos que estejam dispersos no campo da discursividade e que possam ser articulados aos significados que explicam a vida social conforme sua conveniência (Laclau \& Mouffe, 2001). Assim, o FDE, como muitas outras organizações, vive em constante tensão entre uma lógica particular e um contexto dominante cujo modus operandi colide com sua forma de produção do organizar. Mas, assim como Laclau e Mouffe (2001), entendemos que o campo social está sujeito a contingências e que seus deslocamentos e consequências podem proporcionar articulações que dependem da forma como os sujeitos se posicionarão diante dessas situações. Nesse sentido, acreditamos que a experiência do FDE signifique um exemplo de uma contraposição àquilo que os estudos organizacionais predominantemente difundem como forma de organização e gestão, um exemplo daquilo que entendemos como fissuras ou lacunas em nossa realidade social, cuja análise atenta nos fornece novas compreensões sobre as dinâmicas organizacionais. Conforme argumentamos no início do trabalho, o olhar atento às experiências que se situam nas fronteiras da ordem social se constitui em estratégia bastante fecunda para o desenvolvimento de abordagens alternativas nos estudos organizacionais.

\section{REFERÊNCIAS}

Abraham, Y-M. (2007). L'entreprise est-elle nécessaire? In J.-P. Dupuis (Ed.), Sociologie de l'entreprise (pp. 323-374) (2. ed.). Montreal, Canada: Gaëtan Morin.

Alcadipani, R. (2011). Academia e a fábrica de sardinhas. O\&SOrganizações \& Sociedade, 18(57), 345-348.

Alcadipani, R., \& Tureta, C. (2009). Perspectivas críticas no Brasil: Entre a "verdadeira crítica" e o dia a dia. Cadernos EBAPE.BR, 7(3), 505-508.

Alvesson, M., \& Deetz, S. (1996). Critical theory and postmodernism approaches to organizational studies. In S. Clegg, C. Hardy, \& W. Nord (Eds.), Handbook of organization studies. London, Reino Unido: Sage.

Andion, C. (2005). A gestão no campo da economia solidária: Particularidades e desafios. RAC-Revista de Administração Contemporânea, 9(1), 79-101. doi:10.1590/S1415-65552005000100005

Barcellos, R., \& Dellagnelo, E. (2013). A teoria política do discurso como abordagem para o estudo de organizações de resistência: Reflexões sobre o caso do Circuito Fora do Eixo. O\&S-Organizações \& Sociedade, 21(70), 405-424.

Barcellos, R., Dellagnelo, E., \& Salles, H. (2014). Práticas organizacionais e o estabelecimento de lógicas de equivalência: O Circuito Fora do Eixo à luz da teoria política do discurso. RAUSP-Revista de Administração da Universidade de São Paulo, 49(4), 684-697. doi:10.5700/rausp1177

Barcellos, R., \& Diniz, E. (2016). Money is time: How a Brazilian organization has appropriated the time banking concept to nationally support a chain of local artists and cultural producers. VI Organizations, Artifacts and Practices (OAP) Workshop, Lisboa, Portugal.

Barros, A., \& Carrieri, A. (2015). O cotidiano e a história: Construindo novos olhares na Administração. RAE-Revista de Administração de Empresas, 55(2), 151-161. doi:10.1590/So034-759020150205

Barros, A., Cruz, R., Xavier, W., Carrieri, A., \& Lima, G. (2011). Apropriação dos saberes administrativos: Um olhar alternativo sobre o desenvolvimento da área. Revista de Administração Mackenzie, 12(5), 43-67.

Bey, H. (2001). TAZ: Zona autônoma temporária. São Paulo, SP: Conrad.

Böhm, S. (2006). Repositiong organization theory. New York, EUA: Palgrave MacMillan.

Boyle, D. (2003). The new mutualism and the meaning of time banks. Local Economy, 18(3), 253-270. doi:10.1080/0269094032000111048b

Carrieri, A. (2004). O humor como estratégia discursiva de resistência: As charges do SINTELL/MG. O\&S-Organizações \& Sociedade, 11(30), 29-45. doi:10.1590/S1984-92302004000200002

Carrieri, A., Perdigão, D., \& Aguiar, A. (2014). A gestão ordinária dos pequenos negócios: Outro olhar sobre a gestão em estudos organizacionais. RAUSP-Revista de Administração da Universidade de São Paulo, 49(4), 698-713. doi:10.570o/rausp1178

Chanlat, J. (1999). Ciências sociais e management: Reconciliando o econômico e o social. São Paulo, SP: Atlas.

Cheney, G., Cruz, I., Peredo, A., \& Nazareno, E. (2014). Worker cooperatives as an organizational alternative: Challenges, achievements and promise in business governance and ownership. Organization, 21(5), 591-603. doi:10.1177/1350508414539784 
Clegg, S. (1998). As organizações modernas. Lisboa, Portugal: Celta Editora/Oeiras.

Collom, E. (2011). Motivations and differential participation in a community currency system: The dynamics within a local social movement organization. Sociological Forum, 26(1), 144-168. doi:10.1111/j.1573-7861.2010.01228.x

Costa, P., \& Carrion, R. (2008). Situando a economia solidária no campo dos estudos organizacionais. V Encontro de Estudos Organizacionais, Belo Horizonte, MG.

Dellagnelo, E., Böhm, S., \& Mendonça, P. (2014). Organizing resistance movements: The contribution of political discourse theory. RAERevista de Administração de Empresas, 54(2), 141-153. doi:10.1590/ So034-759020140203

Denzin, N. K., \& Lincoln, Y. S. (Orgs.). (2006). O planejamento da pesquisa qualitativa: Teorias e abordagens (2a ed.). Porto Alegre, RS: Artmed.

Duarte, M., \& Alcadipani, R. (2016). Contribuições do organizar (organizing) para os estudos organizacionais. O\&S-Organizações \& Sociedade, 23(76), 57-72. doi:10.1590/1984-9230763

Dumont, L. (2000). Homo aequalis: Gênese e plenitude da ideologia econômica. Bauru, SP: EDUSC.

Echeagaray, M. (2011). Recrear el dinero em uma economía solidaria. POLIS-Revista de La Universidad Bolivariana,10(29), 261-280.

Faria, J., Leal, A. P., Attie, J. P., Hirayama, W. H., Matos, R. D., \& Dutra, R. S. A. (2008). Autogestão e poder: Esquema de análise das relações de poder em organizações com características autogestionárias. $V$ Encontro de Estudos Organizacionais, Belo Horizonte, MG.

Faria, J. (2009). Teoria crítica em estudos organizacionais no Brasil: 0 estado da arte. Cadernos EBAPE.BR, 7(3), 510-515.

Fournier, V., \& Grey, C. (1999). Too much, too little and too often: A critique of du Gay's analysis of enterprise. Organization, 6(1), 107128. doi:10.1177/135050849961005

França, G. (2003). A temática da economia solidária e suas implicações originais para o campo dos estudos organizacionais. RAP-Revista de Administração Pública, 37(1), 11-31.

França, G. (2007). Teoria e prática em economia solidária: Problemática, desafios e vocação. Civitas, 7(1), 155-174. doi:10.15448/19847289.2007 .1 .2041

Fraňková, E., Fousek, J., Kala, L., \& Labohý, J. (2014). Transaction network analysis for studying local exchange trading systems (LETS): Research potentials and limitations. Ecological Economics, 107, 266275. doi:10.1016/j.ecolecon.2014.09.009

Freire, P. (2005). A pedagogia do oprimido (42a ed.). Rio de Janeiro, RJ: Paz e Terra.

Godoy, S. (2006). Estudo de caso qualitativo. In C. Godoy, R. BandeiraDe-Melo, \& A. Silva (Eds.), Pesquisa qualitativa em estudos organizacionais: Paradigmas, estratégias e métodos (pp. 115-146). São Paulo, SP: Saraiva.

Höpfl, H. (2006). Post-bureaucracy and Weber's "modern" bureaucrat. Journal of Organizational Change Management, 19(1), 8-21. doi:10.1108/09534810610643659

Ibarra-Colado, E. (2006). Organization Studies and epistemic coloniality in Latin America: Thinking otherness from the margins. Organization, 13(4), 463-488. doi:10.1177/1350508406065851

Imas, J., \& Weston. A. (2012). From Harare to Rio de Janeiro: KukyaFavela organization of the excluded. Organization, 19(2), 205-227. doi:10.1177/1350508411429397
Innes, J. (2004). Consensus building: Clarifications for the critics. Planning Theory, 3(1), 5-20. doi:10.1177/1473095204042315

Kallinikos, J. (2004). The social foundation of the bureaucratic order. Organization, 11(1), 13-36. doi:10.1177/1350508404039657

Klikauer, T. (2015). What is managerialism? Critical Sociology, 41(7-8), 1103-1119. doi:10.1177/0896920513501351

Laclau, E., \& Mouffe, C. (2001). Hegemony and socialist strategy: Towards a radical democratic politics (2nd ed.). London, Reino Unido: Verso.

Land, C., \& King, D. (2014). Organizing otherwise: Translating anarchism in a voluntary sector organization. Ephemera, 14(4), 923-950.

Magro, M., \& Coutinho, M. (2008). Os sentidos do trabalho para sujeitos inserido em "empreendimentos solidários". Psicologia em Estudo, 13(4), 703-711. doi:10.1590/S1413-73722008000400008

Malatesta, E. (1927). Anarquia e organização. Recuperado de http:// www.marxists.org/portugues/malatesta/1927/mes/anarquia.htm

Marchi, L. (2011). Discutindo o papel da produção independente brasileira no mercado fonográfico em rede. In M. Herschmann (Org.), Nas bordas e fora do mainstream musical: Novas tendências da música independente no início do século XXI (pp. 145-163). São Paulo, SP: Estação das Letras e Cores Editora.

Meira, F. (2014). Liminal organization: Organizational emergence within solidary economy in Brazil. Organization, 21(5), 713-729. doi:10.1177/1350508414537621

Misoczky, M., \& Amantino-De-Andrade, J. (2005). Uma crítica à crítica domesticada nos estudos organizacionais. RAC-Revista de Administração Contemporânea, 9(1), 192-210. doi:10.1590/S141565552005000100010

Misoczky, M., Flores, R., \& Böhm, S. (2008). A práxis da resistência e a hegemonia da organização. O\&S-Organizações \& Sociedade, 15(45), 181-193.

Misoczky, M., Silva, J., \& Flores, R. (2008). Autogestão e práticas organizacionais horizontalizadas: Amplificando sinais. $V$ Encontro Nacional de Estudos Organizacionais da Anpad, Belo Horizonte, MG.

Moraes, J. (2010). Self-management as a toll to organize counterhegemony. O\&S-Organizações \& Sociedade, 17(55), 585-604.

Morais, L., \& Paula, A. P. de. (2010). Identificação ou resistência? Uma análise da constituição subjetiva do policial. RAC-Revista de Administração Contemporânea, 14(4), 633-650. doi:10.1590/S141565552010000400005

Motta, F. P., \& Bresser-Pereira, L. (2004). Introdução à organização burocrática (2a ed.). São Paulo, SP: Pioneira Thomson Learning.

Nakano, D. (2010). A produção independente e a desverticalização da cadeia produtiva da música. Gestão \& Produção, 17(3), 627-638. doi:10.1590/S0104-530X2010000300015

Oliveira, J., \& Cavedon, N. (2015). As tramas políticas emocionais na gênese de processos organizativos em uma organização circense. O\&S-Organizações \& Sociedade, 22(72), 61-78. doi:10.1590/19849230723

Parker, M. (2002). Against management: Organization in the age of managerialism. Cambridge, Reino Unido: Polity.

Parker, M., Fournier, V., \& Reedy, P. (2007). The dictionary of alternatives. New York, EUA: Zed Books. 
Paula, A. P de. (2001). Tragtenberg e a resistência da crítica: Pesquisa e ensino na Administração hoje. RAE-Revista de Administração de Empresas, 41(3), 77-81. doi:10.1590/So034-75902001000300010

Paula, A. P de. (2002). Tragtenberg revisitado: As inexoráveis harmonias administrativas e a burocracia flexível. RAP-Revista de Administração Pública, 36(1), 127-144.

Paula, A. P de. (2013). Abordagem freudo-frankfurtiana, pesquisaação e socioanálise: Uma proposta alternativa para os Estudos Organizacionais. Cadernos EBAPE.BR, 11(4), 520-542. doi:10.1590/ S1679-39512013000400004

Paula, A. P de, Calbino, D., Toledo, D., Tarabal, F., Mascarenhas, L., \& Barreto, R. (2011). A economia solidária e a questão do imaginário: Em busca de novas perspectivas. O\&S-Organizações \& Sociedade, 18(57), 323-333. doi:10.1590/S1984-92302011000200007

Portal Transparência Fora do Eixo. (2013). Programa Políticas Fora do Eixo 2013. Recuperado de http://foradoeixo.org.br/2013/08/04/ programa-partido-fora-do-eixo-2013/

Proudhon, P. (1988). O que é a propriedade? São Paulo, SP: Martins Fontes.

Reedy, P. (2014). Impossible organisations: Anarchism and organisational praxis. Ephemera, 14(4), 639-658.

Rodgers, D., Petersen, J., \& Sandersen, J. (2016). Commemorating alternative organizations and marginalized spaces: The case of forgotten Finntowns. Organization, 23(1), 90-113. doi:10.1177/1350508415605110

Rodrigues, S., \& Carrieri, A. (2001). A tradição anglo-saxônica nos estudos organizacionais brasileiros. RAC-Revista de Administração Contemporânea, 5(Edição Especial), 81-102. doi:10.1590/S141565552001000500005

Rubim, A. (2010). Políticas culturais no governo Lula. In A. Rubim (Org.), Políticas culturais no governo Lula (9-24) Salvador, BA: Edufba.

Santos, B. (2002). Para uma sociologia das ausências e uma sociologia das emergências. Revista Crítica de Ciências Sociais, 63, 237-280.

Schneiberg, M., King, M., \& Smith, T. (2008). Social movements and organizational form: Cooperative alternatives to corporations in the american insurance, dairy, and grain industries. American Sociological Review, 73(4), 635-667. doi:10.1177/000312240807300406
Schwandt, T. A. (2006). Três posturas epistemológicas para a investigação qualitativa: Interpretativismo, hermenêutica e construcionismo social. In N. K. Denzin, \& Y. S. Lincoln (Orgs.), $O$ planejamento da pesquisa qualitativa: Teorias e abordagens (2a ed., pp. 193-217). Porto Alegre, RS: Artmed.

Segnini, L., \& Alcadipani, R. (2014). Poder e resistências nas organizações: A propósito das contribuições de Fernando C. Prestes Motta. RAE-Revista de Administração de Empresas, 54(3), 341-347. doi:10.1590/So034-759020140309

Serva, M. (1997). A racionalidade substantiva demonstrada na prática administrativa. RAE-Revista de Administração de Empresas, 37(2), 18-30. doi:10.1590/So034-75901997000200003.

Solé, A. (2008). L'enterprisation du monde. In J. Chaize, \& T. Felix (Coords.), Repenser L'enterprise (pp. 27-54). Paris, France: Le Cherche Midi.

Spicer, A., Alvesson, M., \& Kärreman, D. (2009). Critical performativity: The unfinished business of critical management studies. Human Relations, 62(4), 537-560. doi:10.1177/0018726708101984

Spicer, A., \& Böhm, S. (2007). Moving management: Theorizing struggles against the hegemony of management. Organization Studies, 28(11), 1667-1698. doi:10.1177/0170840606082219

Stake, R. (2000). Case studies. In N. Denzin, \& Y. Lincoln, Handbook of qualitative research (443-466) (2nd ed.). London, Reino Unido: Sage Publications.

Sutherland, N., Land, C., \& Böhm, S. (2014). Anti-leaders(hip) in social movement organizations: The case of autonomous grassroots groups. Organization, 21(6), 759-781. doi:10.1177/1350508413480254

Tragtenberg, M. (1980). Burocracia e ideologia. São Paulo, SP: Ática.

Tureta, C., \& Araujo, B. (2013). Escolas de samba: Trajetória, contradições e contribuições para os estudos organizacionais. O\&S Organizações \& Sociedade, 20(64), 111-129. doi:10.1590/S198492302013000100008

Wood, T., Jr. (2013). Organizações híbridas. RAE-Revista de Administração de Empresas, 50(2), 241-247. doi:10.1590/So03475902010000200008

Zilio, L., Barcellos, R., Dellagnelo, E., \& Assman, S. (2012, Dezembro). Organizações contra- hegemônicas e a possibilidade de redescoberta da política na modernidade: Uma contribuição a partir do pensamento de Hannah Arendt. Cadernos EBAPE.BR, 10(4), 789-803. 